British Journal of Nutrition (2021), 126, 591-599

(C) The Author(s), 2020. Published by Cambridge University Press on behalf of The Nutrition Society. This is an Open Access article, distributed under the terms of the Creative Commons Attribution licence (http://creativecommons.org/licenses/by/4.0/), which permits unrestricted re-use, distribution, and reproduction in any medium, provided the original work is properly cited.

\title{
Adherence to healthy and sustainable diets is not differentiated by cost, but rather source of foods among young adults in Albania
}

\author{
Erand Llanaj ${ }^{1,2 *} \dagger$ and Giles T. Hanley-Cook ${ }^{3} \dagger$ \\ ${ }^{1}$ Department of Public Health and Epidemiology, Faculty of Medicine, University of Debrecen, 4028 Debrecen, Hungary \\ ${ }^{2}$ Doctoral School of Health Sciences, University of Debrecen, 4028 Debrecen, Hungary \\ ${ }^{3}$ Department of Food Technology, Safety and Health, Faculty of Bioscience Engineering, Ghent University, B-900O Ghent, \\ Belgium
}

(Submitted 26 June 2020 - Final revision received 22 October 2020 - Accepted 29 October 2020 - First published online 4 November 2020 )

\section{Abstract}

High cost of nutritious foods and eating out of home $(\mathrm{OH})$ might be barriers to healthy and sustainable diets. We examined adherence to Dietary Approaches to Stop Hypertension (DASH), EAT-Lancet reference diet (EAT) and Mediterranean diet score (MDS) and the associations with dietary cost and eating OH. We evaluated cross-sectional data from single multiple-pass 24-h diet recalls from 289 young adults (18-24 years) in Tirana, Albania. Dietary cost (in Albanian Lek (ALL)) was estimated by matching food consumption data with retail prices from local fast-food chains, supermarkets, restaurants and food vendors. Poisson regression was fitted to models that included DASH, EAT and MDS as dependent variables to assess associations between healthy sustainable diet indicators and dietary cost and eating OH. Adjusted models were controlled for BMI, sex and total energy intake (kJ) using the residual method. Our findings indicate relatively poor adherence to healthy and sustainable dietary patterns among young men and women in Albania. Furthermore, better adherence to DASH, EAT or MDS was not associated with dietary cost (per $100 \mathrm{ALL}$; range incidence rate ratios (IRR): 0.97-1.00; all (un-)adjusted $P>0 \cdot 05$ ). Nonetheless, eating OH was related to lower adherence to DASH (IRR: $0.79 ; P=0.003$ ) and MDS (IRR: $0.69 ; P<0.001$ ). In conclusion, adherence to health and sustainable dietary patterns was poor and not differentiated by cost, but rather source of foods (i.e. OH or at home). Further research on the potential public and environmental health effects of these findings is warranted in Albania.

\section{Key words: 24-h diet recall: Albania: Dietary cost: Dietary patterns: Sustainable diets: Young adults}

Malnutrition, in all its forms, has been increasing around the globe $^{(1,2)}$, particularly in low- and middle-income countries ${ }^{(3)}$. This has led to a large burden of cardiometabolic morbidity ${ }^{(4,5)}$ and mortality ${ }^{(6)}$, predominantly from diet-related noncommunicable diseases (NCD). This unfavourable dietary shift, commonly referred to as the nutrition transition, ${ }^{(7)}$, is marked by a departure from prudent diets, that is, high in whole-grain cereals, fruit and vegetables, legumes, nuts, and fibre, towards dietary patterns linked to the development of metabolic disorders and consequent diet-related NCD of high public health significance (i.e. CVD, type 2 diabetes and several types of cancer) ${ }^{(8-10)}$.

One major lifestyle change, which has taken place over the last decades, is the growing trend of consuming food and drinks out of home $(\mathrm{OH})^{(2,11-13)}$. The economies of scale and scope, food processing and packaging have resulted in lower prices and more convenient purchasing of food and drinks high in sugar, fat and $\mathrm{Na}$, although this may vary depending on the income and development level of a country ${ }^{(14,15)}$. The consequence is that these products have become accessible and marketed especially to vulnerable groups, such as children, poorer socio-economic groups, young adults, students and ethnic minorities $^{(16,17)}$.

Eating $\mathrm{OH}$ has been associated with higher energy and fat intake and lower micronutrient intake ${ }^{(12)}$, as well as higher rates of overweight and obesity ${ }^{(18)}$. In contrast, eating at home (AH) has been linked to more favourable dietary profiles ${ }^{(19,20)}$. However, research indicates that consumption of home-prepared food is not a perquisite for achieving higher dietary quality ${ }^{(21,22)}$. Despite the nuanced picture of eating $\mathrm{OH}$ and diet quality, consumption of foods prepared $\mathrm{OH}$ has been linked to elevated cardiometabolic risks ${ }^{(23)}$ and conditions such as prehypertension and hypertension, particularly among young adults ${ }^{(24)}$.

Abbreviations: AH, at home; ALL, Albanian Lek; DASH, Dietary Approaches to Stop Hypertension; EAT, EAT-Lancet reference diet; 24HR, 24-hour recall; IQR, interquartile range; MDS, Mediterranean diet score; NCD, non-communicable disease; $\mathrm{OH}$, out of home.

* Corresponding author: Erand Llanaj, email erand.llanaj@med.unideb.hu

$\dagger$ These authors contributed equally to the work. 
Nevertheless, there are established food-based dietary guidelines and patterns that serve to reduce the risk of diet-related $\mathrm{NCD}^{(25,26)}$. To illustrate, the Mediterranean diet has been associated with a lower risk of CVD among adults at risk ${ }^{(27)}$. In addition, adherence to Dietary Approaches to Stop Hypertension (DASH) has been shown to significantly lower the risk of high blood pressure $^{(28,29)}$. Furthermore, Knuppel et al. ${ }^{(30)}$ indicated that the EAT-Lancet reference diet score (EAT) was associated with lower odds of major health outcomes, such as ischaemic heart disease and diabetes, in adults of the European Prospective Investigation into Cancer and Nutrition (EPIC)-Oxford cohort.

Besides the global health and nutritional concerns, what we are eating and how we are producing food are also exerting huge environmental pressures ${ }^{(31)}$. Food and nutrition has emerged as one of the most promising levers to improve health and environmental sustainability ${ }^{(32)}$. Clark et al. ${ }^{(33)}$ demonstrated that healthpromoting dietary patterns often have lower environmental impacts, suggesting that dietary transitions that might lower the risk of NCD might also support the attainment of environmental sustainability targets. To address the need to feed a growing global population a healthy diet from sustainable food systems, Willett et al. ${ }^{(34)}$ defined a universal reference diet that aims to promote both human health and environmental sustainability.

Although the nutritional composition and quality of $\mathrm{OH}$ dietary intake have been extensively studied, the relationships between $\mathrm{OH}$ eating and healthy and sustainable dietary patterns in the Balkan Peninsula remain speculative. Furthermore, dietary transition towards nutritious and more sustainable food and drink consumption necessitates economic considerations. To address these knowledge gaps, we provide a cross-sectional analysis on adherence to, and cost of diets shown to support health, reduce disease risk and promote environmental sustainability among young adults in Albania (i.e. an upper middleincome country in South-eastern Europe).

\section{Methods}

This is a secondary analysis of observational data from a crosssectional epidemiological study conducted between October 2015 and February 2016 in Tirana, Albania ${ }^{(35)}$.

\section{Data sources}

Dietary intake data were collected using a single automated multiple-pass 24-h diet recall $(24 \mathrm{HR})^{(36)}$, from a cross-sectional study carried out between October 2015 and February 2016 in Tirana, Albania. The survey included 289 young adults (18-24 years), who were studying at the three largest universities in Albania (36-38\% of country's bachelor students at the time of data collection ${ }^{(37)}$ ), namely University of Tirana, University of Medicine Tirana and Polytechnic University of Tirana. The following eligibility criteria were used for subject inclusion: (i) enrolled in one of the aforementioned universities and (ii) studying in any of the bachelor degree programmes. The later restriction was applied with the intent to exclude students enrolled in postgraduate programmes because in Albania these programmes are often part time and these students typically work whilst studying and are thus not regularly in contact with the typical student food environment. Reported dietary intake was classified into $\mathrm{AH}$ and $\mathrm{OH}$ food and drinks, where the latter was defined as: all food items not prepared $\mathrm{AH}$ and obtained from fast-food companies, restaurants, street-food vendors and other $\mathrm{OH}$ sources of food, including food products purchased ready-to-eat from food stores, such as supermarkets, convenience stores and some special food markets. Retail prices for all items (in Albanian Lek (ALL)) were provided by local fastfood companies, supermarkets, restaurants and other food vendors. Food consumption data were matched with price data to provide estimates of dietary cost. Height $(\mathrm{cm})$ and weight $(\mathrm{kg})$ of the participants were measured in duplicate by trained interviewers. A third measurement was performed if the first two measurements diverged by $\geq 100 \mathrm{~g}$ for weight and $\geq 1 \mathrm{~cm}$ for height. A more detailed description of study design, study sample, definition of eating $\mathrm{OH}$, validity of the recall method, as well as food composition and cost data is available in Llanaj et al. ${ }^{(35)}$.

\section{Sample size}

For our secondary analyses on observational data, we used the formula by Signorini ${ }^{(38)}$ to determine the sample size for simple Poisson regression, using the following assumptions: $90 \%$ power $(1-\beta), 5 \%$ significance level $(\alpha)$, intercept $0\left(\beta_{0}\right)$, slope $0 \cdot 1\left(\beta_{1}\right)$, mean of cost $0 \cdot 8$ (in $1000 \mathrm{ALL} ; \mu$. $\mathrm{X}_{1}$ ), variance of cost 5 (in $\left.1000 \mathrm{ALL} ; \sigma^{2} . \mathrm{X}_{1}\right)$, mean exposure time $1 \mathrm{~d}(\mu \mathrm{T})$ and over dispersion $1(\varphi)$. Our calculations resulted in a required sample size of 202 participants.

\section{Dietary indices and classifications}

Adherence to the Mediterranean diet score (MDS) was computed according to the index developed by Serra-Majem et al. ${ }^{(39)}$, for subjects aged up to 24 years. The index ranges from 0 to 12 , based on a sixteen-question test and is founded on principles sustaining Mediterranean dietary patterns as well as those that undermine it. Questions denoting a negative connotation with respect to the Mediterranean diet were assigned a value of -1 (e.g. eating at a fast-food restaurant), and those with a positive aspect +1 (e.g. use of olive oil).

In addition, the DASH index, previously used by Mellen et al. ${ }^{(40)}$, was calculated for our sample of young Albanian women and men. This version of the DASH index is an entirely nutrientbased DASH diet score, based on target nutrient values from the DASH diet used in two clinical trials ${ }^{(41,42)}$. Individuals who meet the goal for each component receive 1 point, those who meet an intermediate goal, defined as the midpoint between the DASH diet goal and the nutrient content of the DASH control diet ${ }^{(41)}$, receive 0.5 point and those who meet neither goal received 0 points. A total score was generated by summing all nutrient components, resulting in a minimum of 0 and a maximum of 9 points. Intake of energy-yielding nutrients was calculated as a percentage of total energy intake and intake for other nutrients was adjusted for quantity (g or mg) per $4184 \mathrm{~kJ}$ (1000 kcal).

Dietary intake data from our sample were also compared with the EAT-Lancet reference diet for healthy diets from sustainable food systems ${ }^{(34)}$. An EAT score (0-14 points) was calculated based on the adherence to fourteen key dietary recommendations, as 
described in Knuppel et al. ${ }^{(30)}$. EAT ranges correspond to the average energy needs $(10460 \mathrm{~kJ} / \mathrm{d}(2500 \mathrm{kcal} / \mathrm{d}))$ of a 30-year-old woman weighing $60 \mathrm{~kg}$ and whose physical activity level is between moderate and high $(1 \cdot 7-2 \cdot 0)^{(34)}$. Hence, calculations for estimated food group intakes were standardised for an energy intake of $10460 \mathrm{~kJ} / \mathrm{d}(2500 \mathrm{kcal} / \mathrm{d})$.

Participants were classified as 'substantial AH eaters' if $\leq 20 \%$ of their total dietary energy intake came from foods and drinks prepared $\mathrm{OH}$ and as 'substantial $\mathrm{OH}$ eaters' if this percentage was higher than $20 \%$.

\section{Dietary adherence levels}

A dichotomous outcome was created for DASH, with individuals meeting approximately half of the DASH targets (score $\geq 4.5$ points) considered 'DASH accordant', while others 'DASH non-accordant ${ }^{\text {(40) }}$. EAT and MDS adherence levels where determined by dividing the score distributions into three categories: (1) low adherence ( $<25$ th percentile), (2) moderate adherence (between 25th and 75th percentiles) and (3) high adherence ( $>75$ th percentile).

\section{Statistical analysis}

Poisson regression was fit to models that included DASH, EAT and MDS as dependent variables, given their discrete, bounded nature and equidispersion of the distributions, to assess associations between healthy sustainable diet indicators and dietary cost and $\mathrm{OH}$ eating. Adjusted models controlled for BMI, sex and total energy intake $(\mathrm{kJ})$ using the residual method ${ }^{(43)}$. To examine any differences in the association between dietary indices and cost by level of eating $\mathrm{OH}$, we tested interaction terms between dietary cost and $\mathrm{OH}$ as a binary variable (i.e. 0 for $\leq 20 \%$ and 1 for $>20 \%$ total energy $(\mathrm{kJ} / \mathrm{d}))$. Moreover, for further exploratory analyses, ordinary least-squares regression was fit to models that included BMI as the dependent variable and dietary indices as the predictors.

Numerical values were accompanied by their $95 \%$ CI or interquartile range (IQR) where applicable and Student's $t$ test or the Mann-Whitney $U$ test was used to test for differences between sexes. Food intake data were processed using the Lucille Food Intake software. Data management and statistical analyses were performed with Stata 14.2 and R Statistics 3.14. A two-sided significance level of $P<0.05$ was applied for all analyses.

\section{Ethics}

All subjects gave their written informed consent before participating in the study. The study protocol and methods were approved by the Medical Ethics Committee of Ghent University (EC/2015/1118), the Directorate of Health Care at the Ministry of Health in Albania (MSH/2015/LL-13-1) and the Ethics Committee of the University of Medicine Tirana.

\section{Results}

\section{Sample characteristics}

$24 \mathrm{HR}$ data were obtained for 289 young adults (87\% women; age range: $18-24$ years; Table 1). DASH, EAT and MDS were (median (IQR)) 3.5 (IQR 2.5, 4), 2 (IQR 1, 2) and 4 (IQR 3, 6), respectively. Furthermore, 237 (82\%) subjects were considered substantial $\mathrm{OH}$ eaters (i.e. $>20 \% \mathrm{~kJ} / \mathrm{d}$ ). Moreover, mean (SD) dietary energy intake was 10088 (sD 2506) kJ/d, dietary cost was 806 (sD 284) ALL/d and BMI was 21.4 (sD 3.2) kg/m². Adherence to all three dietary patterns was poor, in particular, for intakes of vegetables, fruits, sweeteners and animal-source foods (Fig. 1).

Our findings indicate non-significant differences in most (micro) nutrient intakes (except carbohydrates and $\mathrm{Na}$ ) between women and men (Table 1). However, height $(\mathrm{cm})$, weight $(\mathrm{kg})$, total energy intake $(\mathrm{kJ})$ from $\mathrm{OH}$ consumption and BMI were significantly different between women and men, with the latter having higher values. Anthropometric measurements were not significantly different among substantial $\mathrm{AH}$ and $\mathrm{OH}$ eaters $(P>0.05$; results available on request). Dietary intakes of total fats (\%E), SFA, sugar (both \%E and $\mathrm{g} / \mathrm{d}$ ), cholesterol (both $\mathrm{mg} / 4184 \mathrm{~kJ}$ and $\mathrm{g} / \mathrm{d}$ ) and $\mathrm{Na}$ (both $\mathrm{mg} / 4184 \mathrm{~kJ}$ and $\mathrm{g} / \mathrm{d}$ ) were higher than the reference ranges for both sexes. In contrast, dietary intakes of carbohydrates, dietary fibres (both $\mathrm{g} / 4184 \mathrm{~kJ}$ and $\% \mathrm{E}$ ), $\mathrm{Mg}$ and $\mathrm{K}$ (both $\mathrm{mg} / 4184 \mathrm{~kJ}$ and $\mathrm{g} / \mathrm{d}$ ) were significantly lower than the reference ranges for both sexes.

When comparing substantial $\mathrm{OH}$ and $\mathrm{AH}$ consumers, there was a significant positive association $(P<0.05)$ between adhering to health-promoting dietary patterns and being a substantial $\mathrm{AH}$ eater, for both DASH ((non)-accordant) and MDS (low, moderate and high; Table 2).

\section{Associations between dietary indices, cost, out of home eating and $\mathrm{BMI}$}

DASH, EAT and MDS were consistently neutrally associated with dietary cost (in ALL) among young men and women (range incidence rate ratios: 0.97-1.00; all $P>0.05$; Table 3; Fig. 2). Unadjusted models indicated similar results and are therefore not shown. Nevertheless, eating $\mathrm{OH}$ was related to lower adherence to DASH (incidence rate ratio: $0.79 ; P=0.003$ ) and MDS (incidence rate ratio: $0.69 ; P<0 \cdot 001$ ), but non-significant for EAT $(P>0.05)$. When comparing dietary cost of adherence levels, stratified by substantial $\mathrm{AH} v$. $\mathrm{OH}$ eaters, there was no statistical differences between those eating more $\mathrm{OH}$ and those eating more $\mathrm{AH}$ (Fig. 2). Furthermore, the interaction terms between dietary indices and $\mathrm{OH}$ were also non-significant (all $P>0 \cdot 05$ ).

Further exploratory analyses indicated that for each onepoint increase in healthy and sustainable diet scores, BMI changed by between -0.3 and $0.2 \mathrm{~kg} / \mathrm{m}^{2}$ (Table 4). However, only the unadjusted association between BMI and MDS was significant $(\beta: 0 \cdot 2$ (SE $0 \cdot 1) ; P=0 \cdot 028)$.

\section{Discussion}

Our study reports that adherence to healthy and sustainable dietary patterns is suboptimal among young adults in Albania. However, our findings indicate that a transition to more human and environmental health-promoting diets is not constrained by cost, but rather by the level of $\mathrm{OH}$ eating. In parallel to priority action areas set by the National Program on Prevention and 
Table 1. Anthropometric measurements and dietary intake, cost and indices from our sample of young adults in Albania§

(Mean values and $95 \%$ confidence intervals; median values and interquartile ranges (IQR))

\begin{tabular}{|c|c|c|c|c|c|c|c|c|c|c|c|c|c|c|}
\hline \multirow[b]{3}{*}{ Variable } & \multicolumn{4}{|c|}{ Total $(n$ 289) } & \multicolumn{3}{|c|}{ Females $(n 252) \|$} & \multicolumn{4}{|c|}{ Males $(n 37)$} & \multirow{2}{*}{\multicolumn{2}{|c|}{ Reference range }} & \multirow[b]{3}{*}{$P \dagger$} \\
\hline & \multirow[b]{2}{*}{ Mean } & & \multicolumn{2}{|c|}{$95 \% \mathrm{Cl}$} & \multirow[b]{2}{*}{ Mean } & \multicolumn{2}{|c|}{$95 \% \mathrm{Cl}$} & \multirow[b]{2}{*}{ Mean } & & \multicolumn{2}{|c|}{$95 \% \mathrm{Cl}$} & & & \\
\hline & & & Lower & Upper & & Lower & Upper & & & Lower & Upper & Range & Source & \\
\hline Height (cm) & $165 \cdot 6$ & & $164 \cdot 6$ & $166 \cdot 6$ & $164 \cdot 2$ & $163 \cdot 4$ & $165 \cdot 0$ & $176 \cdot 7$ & & $176 \cdot 0$ & $177 \cdot 3$ & $\mathrm{~N}$ & & $* * *$ \\
\hline Weight (kg) & 58.9 & & 57.7 & 60.1 & 56.9 & $56 \cdot 0$ & 57.9 & 74.0 & & $73 \cdot 1$ & $75 \cdot 0$ & $\mathrm{~N}$ & & $\star \star \star *$ \\
\hline Total energy (kJ) & $10089 \cdot 7$ & & 9799.6 & $10379 \cdot 7$ & 9762.9 & $9469 \cdot 6$ & $10056 \cdot 2$ & $12385 \cdot 1$ & & $11627 \cdot 3$ & $13143 \cdot 2$ & $\mathrm{~N}$ & & *** \\
\hline Energy $\mathrm{OH}(\mathrm{kJ})$ & 4891.1 & & 4552.2 & 5230.0 & 4517.5 & 4184.0 & 4851.0 & 7332.9 & & 6367.2 & 8298.5 & $\mathrm{~N}$ & & $\star \star \star *$ \\
\hline BMI $\left(\mathrm{kg} / \mathrm{m}^{2}\right)$ & 21.45 & & 21.08 & 21.8 & $21 \cdot 1$ & $20 \cdot 8$ & 21.5 & 23.8 & & 23.4 & $24 \cdot 1$ & $20-25$ & (25) & *** \\
\hline Total fats (\%E) & $34.9 \S$ & & 34.0 & 35.8 & $34.8 \S$ & 33.8 & 35.7 & $35.8 \S$ & & 33.9 & 37.7 & $15-30$ & (25) & NS \\
\hline SFA $(\% E)$ & $11.9 \S$ & & 11.5 & 12.4 & $11.8 \S$ & 11.3 & $12 \cdot 3$ & $13 \cdot 1 \S$ & & 11.9 & 14.4 & $0-10$ & $(25,34)$ & NS \\
\hline PUFA (\%E) & 4.2 & & $4 \cdot 0$ & 4.3 & $4 \cdot 1$ & 4.0 & 4.3 & 4.2 & & 3.9 & 4.5 & $3-7$ & (25) & NS \\
\hline Protein (\%E) & $14 \cdot 2$ & & 13.7 & 14.7 & $14 \cdot 1$ & 13.5 & 14.6 & $15 \cdot 3$ & & 14.1 & 16.5 & $10-15$ & (25) & NS \\
\hline Carbohydrates (\%E) & $51.6 \S$ & & 50.5 & 52.8 & $52 \cdot 1 \S$ & 50.8 & 53.3 & $48.4 \S$ & & 45.9 & 50.9 & $55-75$ & (25) & NS \\
\hline Sugar $(\% \mathrm{E})$ & $18.2 \S$ & & $17 \cdot 2$ & 19.2 & $18 \cdot 7 \S$ & 17.7 & 19.8 & $14.6 \S$ & & 11.9 & $17 \cdot 2$ & $\leq 10 ; \leq 8.2$ & $(25,34)$ & ** \\
\hline Sugar $(\mathrm{g})$ & $108.9 \S$ & & 102.5 & $115 \cdot 3$ & $110.2 \S$ & 103.6 & 116.9 & $110.6 \S$ & & 89.3 & 131.8 & $\leq 31$ & (34) & NS \\
\hline Dietary fibres (g/4184 kJ) & $12.9 \S$ & & $12 \cdot 3$ & 13.6 & $13.1 \S$ & 12.4 & 13.8 & $11.8 \S$ & & 10.1 & 13.4 & $\geq 14.8$ & (40) & * \\
\hline Dietary fibres (\%E) & $2 \cdot 1 \S$ & & 1.8 & $2 \cdot 3$ & $2 \cdot 1 \S$ & 1.9 & 2.2 & $2 \cdot 1 \S$ & & 1.8 & 2.4 & $\geq 7$ & (34) & NS \\
\hline $\mathrm{Mg}(\mathrm{mg} / 4184 \mathrm{~kJ})$ & $102.0 \S$ & & 98.9 & $105 \cdot 1$ & $102.6 \S$ & 99.2 & 106.0 & $97.6 \S$ & & 91.1 & 104.0 & $\geq 238$ & (40) & NS \\
\hline $\mathrm{Ca}(\mathrm{mg} / 4184 \mathrm{~kJ})$ & $755 \cdot 8$ & & $706 \cdot 9$ & 804.8 & 755.0 & 701.8 & $808 \cdot 1$ & $762 \cdot 1$ & & 634.0 & $890 \cdot 3$ & $\geq 590$ & (40) & NS \\
\hline $\mathrm{K}(\mathrm{mg} / 4184 \mathrm{~kJ})$ & $1196.6 \S$ & & $1156 \cdot 6$ & 1236.5 & $1206.9 \S$ & 1163.9 & $1249 \cdot 8$ & $1124 \cdot 1 \S$ & & $1012 \cdot 6$ & 1235.5 & $\geq 2238$ & (40) & NS \\
\hline $\mathrm{K}(\mathrm{mg})$ & $2879.2 \S$ & & $2756 \cdot 9$ & 3001.5 & $2853.6 \S$ & $2727 \cdot 0$ & $2980 \cdot 1$ & $3277.3 \S$ & & 2928.6 & $3626 \cdot 1$ & $\geq 4100$ & (34) & NS \\
\hline Cholesterol (mg/4184 kJ) & $95.5 \S$ & & 89.2 & 101.8 & $94.0 \S$ & $87 \cdot 1$ & $100 \cdot 9$ & $106.0 \S$ & & 90.2 & 121.8 & $\leq 71.4$ & (40) & NS \\
\hline Cholesterol (mg) & $232 \cdot 2 \S$ & & $215 \cdot 3$ & 249.1 & $222.8 \S$ & $205 \cdot 3$ & $240 \cdot 3$ & $313.0 \S$ & & 263.2 & 362.8 & $\leq 125 \cdot 2$ & (34) & $\star \star \star *$ \\
\hline $\mathrm{Na}(\mathrm{mg} / 4184 \mathrm{~kJ})$ & 963.9 & & 914.7 & $1013 \cdot 1$ & 944.6 & $893 \cdot 1$ & 996.1 & 1099.6 & & $942 \cdot 0$ & $1257 \cdot 1$ & $\leq 1143$ & (40) & NS \\
\hline $\mathrm{Na}(\mathrm{mg})$ & $2343.8 \S$ & & $2205 \cdot 9$ & $2481 \cdot 7$ & $2258.5 \S$ & 2118.0 & 2398.9 & $3180 \cdot 1 \S$ & & 2773.3 & 3586.9 & $\leq 2000$ & (44) & $\star \star \star *$ \\
\hline Cost (ALL) & 835.6 & & 763.5 & $907 \cdot 7$ & 796.6 & $762 \cdot 3$ & 830.9 & 874.6 & & 764.7 & 984.5 & $\mathrm{~N}$ & & NS \\
\hline DASH score & & & & & & & & & & & & $0-9$ & (40) & NS $\ddagger$ \\
\hline $\begin{array}{l}\text { Median } \\
\text { QRB }\end{array}$ & & 3.5 & & & & 3.5 & & & 3.0 & & & & & \\
\hline IQR & & $2 \cdot 5,4 \cdot 0$ & & & & $2 \cdot 5,4.0$ & & & $2 \cdot 5,4.0$ & & & & & \\
\hline EAT-Lancet score & & & & & & & & & & & & $0-14$ & (30) & NS $\ddagger$ \\
\hline Median & & 1.0 & & & & 1.0 & & & 1.0 & & & & & \\
\hline IQR & & $1 \cdot 0,2 \cdot 0$ & & & & $1 \cdot 0,2 \cdot 0$ & & & $1 \cdot 0,2 \cdot 0$ & & & & & \\
\hline Mediterranean diet score & & & & & & & & & & & & $0-12$ & (39) & NS $\ddagger$ \\
\hline Median & & 4.0 & & & & 5.0 & & & 4.0 & & & & & \\
\hline IQR & & $3 \cdot 0,6 \cdot 0$ & & & & $3 \cdot 0,6 \cdot 0$ & & & $3 \cdot 0,5 \cdot 0$ & & & & & \\
\hline
\end{tabular}

NA, not applicable; OH, out of home; \%E, percentage of total energy intake; ALL, Albanian Lek; DASH, Dietary Approaches to Stop Hypertension.

$\dagger P$ value for difference between sexes by Student's $t$ test (unless otherwise indicated).

Than

. Proportion of female students at study universities varied from 86 to $90 \%$ (http://www.instat.gov.al/media/4616/tab4.xlsx). 


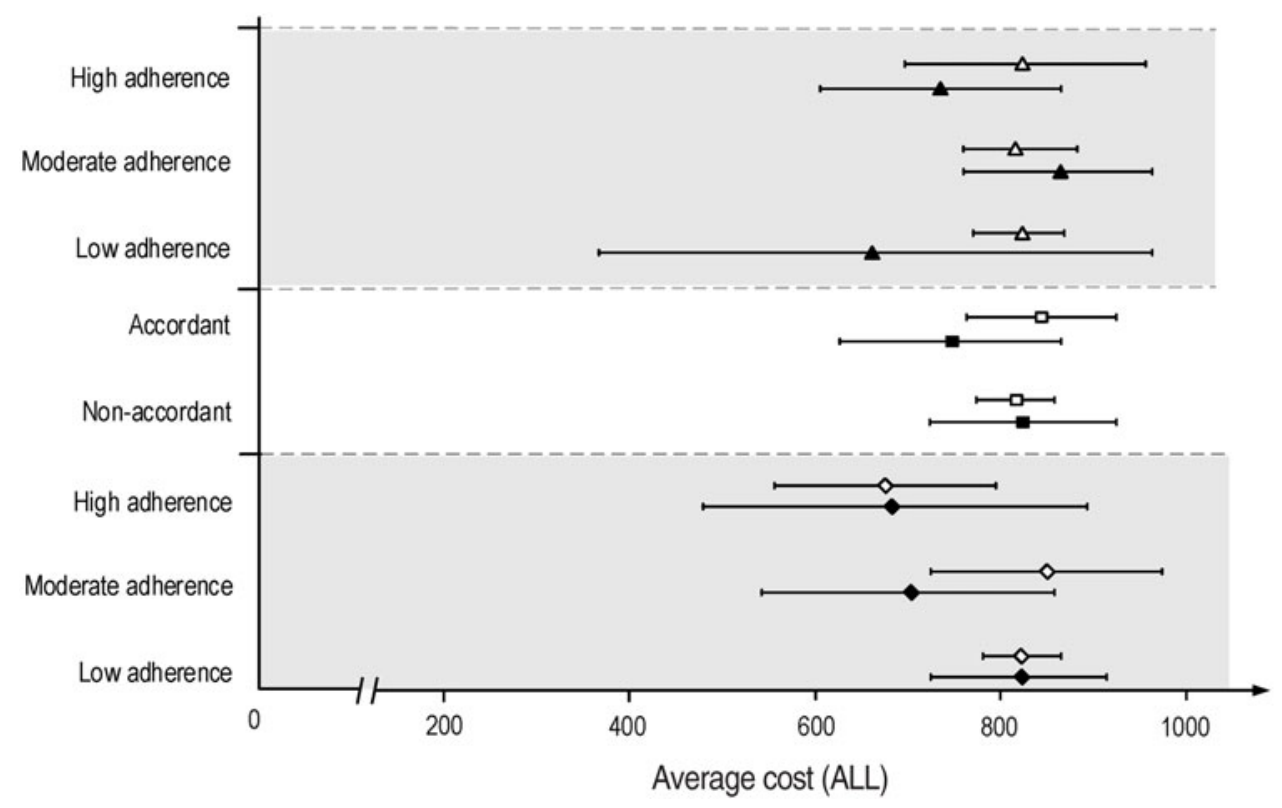

Fig. 1. Adherence to EAT-Lancet, Dietary Approaches to Stop Hypertension (DASH) and Mediterranean diet reference intake values among young adults in Albania. ALL, Albanian Lek (1 ALL approximately 0.0081 Euro). $\mathbf{\square}$, DASH diet; $\bullet$, EAT-Lancet reference diet; $\mathbf{\Delta}$, Mediterranean diet; $\mathbf{\bullet} \mathbf{\Delta}$, substantial at home eaters; $\diamond \square \Delta$, substantial out of home eaters.

Control of NCD in Albania (2016-2020) and National Action Plan for Food and Nutrition (2013-2020), our study advocates for multi-sectoral food and nutrition policies and integrated programmes $^{(45)}$ (e.g. regulation of university food environments, such as student restaurants and canteens) targeting unhealthy $\mathrm{OH}$ eating and championing nutritious and sustainable diets for students in Tirana.

Young adults around the globe play a critical role in the discourse on environmental sustainability, by encouraging social change and sparking political action. Nevertheless, considering the detrimental planetary health impact of current food systems ${ }^{(46)}$, a large majority of the EAT-Lancet reference values, in particular vegetable, fruit, sweetener and limited animalsource food consumption, were not attained by young Albanian men and women. At present, recommendations on 'Healthy Nutrition in Albania' (i.e. national food-based dietary guideline ${ }^{(47)}$ ) fail to include sustainability criteria, although there is mounting evidence linking overconsumption of, in particular, red and ultra-processed meat products with detrimental human and environmental health outcomes ${ }^{(33,48,49)}$. Furthermore, our study participants' dietary intakes indicate 'non-accordance' to DASH guidelines, which is advocated to promote cardiovascular health ${ }^{(28)}$, and low/moderate adherence to MDS, similar to previous studies in the Mediterranean basin ${ }^{(50,51)}$. Thus, our findings offer novel insights into contemporary food and drink consumption among Albanian university students, and key dietary recommendations which might require special attention during nutrition/public health education, such as the importance of fibre, fruit, vegetable and whole-grain intake and the substitution of saturated fats by MUFA/PUFA sources.

Our findings that adherence to DASH and MDS was differentiated by $\mathrm{OH}$ eating are supported by previous research linking
$\mathrm{OH}$ eating to increased energy intake ${ }^{(52)}$, decreased intake of fruit and vegetables ${ }^{(53)}$ and lower intakes of micronutrients ${ }^{(12)}$. Furthermore, Fleischhacker et al. ${ }^{(54)}$ reported that living in an area with a higher access to fast food (e.g. student areas in Tirana) was related to increased $\mathrm{OH}$ consumption. Our lack of association between EAT and $\mathrm{OH}$ eating might be explained by the absence of lower bound intake values (i.e. $0 \mathrm{~g} / \mathrm{d}$ ) for various dietary recommendations leading to positively scoring nonconsumption $^{(55)}$. Nonetheless, dietary patterns of young adults in our survey were poor, regardless of predominantly $\mathrm{AH}$ or $\mathrm{OH}$ eating ${ }^{(35)}$. We argue that these findings are not only a consequence of inappropriate quantity and quality of food and drinks in the Albanian diet ${ }^{(12)}$, but fundamentally a consequence of a global challenge: food systems that fail to provide everyone with healthy, safe, affordable and sustainable diets ${ }^{(56)}$. The economic, social and environmental costs of further inaction will hinder the growth and development of individuals and societies for decades to come ${ }^{(45,57)}$. As the Lancet Series on the 'Double Burden of Malnutrition' shows, the complex interconnected biological and social pathways of all forms of malnutrition are difficult to disrupt through siloed interventions and require societal shifts that can be scaled up and sustained over decades ${ }^{(1,58)}$. Further studies are needed to determine the food system determinants as well as other social drivers (e.g. food deserts, employment conditions) of poor dietary intake in Albania.

In contrast to previous research on the dietary cost of $\mathrm{DASH}^{(59)}, \mathrm{EAT}^{(60)}$ and $\mathrm{MDS}^{(61)}$, our results indicate that higher adherence to these dietary patterns was not associated with increased food and drink expenditure. Nevertheless, our coefficients might be attenuated due to the overall poor adherence to healthy and sustainable dietary patterns among university students in Albania. Thus, suboptimal diets might still be explained 
by economic constraints, since food prices influence food choices and constitute a major barrier to dietary change ${ }^{(62)}$

The first limitation of our observational analysis is the single $24 \mathrm{HR}$, obtained from a relatively small sample of young adults in Tirana. Although $24 \mathrm{HR}$ provide a higher degree of accuracy for assessing food and nutrient intake relative to FFQ, such dietary assessment methods are prone to measurement error due to respondent memory lapses and social desirability/ approval of specific food and drinks ${ }^{(63)}$. Moreover, $24 \mathrm{HR}$ are appropriate to estimate population average dietary intakes, but do not account for intra-person variability ${ }^{(64)}$ and thus estimation of usual dietary intake ${ }^{(65)}$. Second, due to the crosssectional nature, our study was unable to assess relationships between DASH, EAT and MDS and long-term health outcome and/or environmental impacts in Albania. At the time of the research, the EAT-Lancet dietary pattern was not yet promoted (or adopted in Albanian food guides), therefore necessitating caution when interpretation our findings. Third, the population under investigation was composed mainly of female university students, which might hamper generalisability. However, this high representation is reflective of the sex composition of the three public universities the participants were recruited from, which varied between 86 and $90 \%{ }^{(66)}$. Fourth, our study was unable to provide more detailed data on the (perceived) socio-economic status of university students, a knowledge gap to be addressed by future research (i.e. potential missing confounding, as previous studies have reported that wealth status influences food choice and subsequent diet quality $\left.{ }^{(67)}\right)$. Nonetheless, we argue that most Albanian students are financially constrained (although not captured by our study due to unavailable data), as supported by recent mass student protests due to hiked university fees ${ }^{(68)}$. Last, we were unable to describe, in detail, the student food environment (fast- and street food vendors clustered around the faculties or their residence areas $\left.{ }^{(69)}\right)$. Future public health research in Albania must aim to capture students' access to healthy $\mathrm{OH}$ options, the degree of processing of foods and characterisation of university housing, such as kitchen spaces, in order to better understand barriers for the adoption of healthy and sustainable dietary patterns among youth in Albania.

Our study highlights the need to establish and integrate young adulthood nutrition and health in, at present absent ${ }^{(70)}$, (sub)-national surveillance and monitoring systems (e.g. national food intake survey). Furthermore, given the known complexity of dietary behaviours and the wide range of external influences on dietary patterns during this life period, championing sustainable diets in Albania will require pro-active collaboration between a wide range of actors and policies throughout the food system, including the active engagement of university students. At present, an unprecedented opportunity for action exists across South-eastern Europe, within the frameworks of the United Nations Decade of Action on Nutrition (2016-2025) and the 2030 Agenda for Sustainable Development. Thus, further prospective epidemiological studies on the potential public and environmental health effects of our findings (and potential dietary shifts) are warranted in Albania and the Western Balkans. 
Table 3. Associations between healthy and sustainable diet indicators, dietary cost and out of home (OH) eating among young adults in Albania $(n 289)^{*}$ ( $\beta$-Coefficients and standard errors)

\begin{tabular}{|c|c|c|c|c|c|c|c|c|c|}
\hline \multirow[b]{2}{*}{ Independent variable } & \multicolumn{3}{|c|}{ DASH (0-9 points) } & \multicolumn{3}{|c|}{ EAT (0-14 points) } & \multicolumn{3}{|c|}{ MDS (0-12 points) } \\
\hline & $\beta$ & SE & $P$ & $\beta$ & SE & $P$ & $\beta$ & SE & $P$ \\
\hline Cost (per $100 \mathrm{ALL}$ ) & 0 & 0.01 & 0.77 & -0.02 & 0.02 & 0.33 & -0.01 & 0.01 & 0.24 \\
\hline $\mathrm{OH}$ eating & -0.23 & 0.08 & 0.003 & -0.12 & 0.12 & 0.29 & -0.38 & 0.07 & $<0.001$ \\
\hline Cost $\times \mathrm{OH}$ eating & 0 & 0.03 & 0.80 & 0.07 & 0.05 & 0.15 & 0.01 & 0.02 & 0.83 \\
\hline
\end{tabular}

DASH, Dietary Approaches to Stop Hypertension; EAT, EAT-Lancet diet score; MDS, Mediterranean diet score; $\beta$, Poisson regression $\beta$-coefficient; ALL, Albanian Lek.

* Multivariable-adjusted models include BMI, sex and 'total energy intake (kJ)' as confounders.

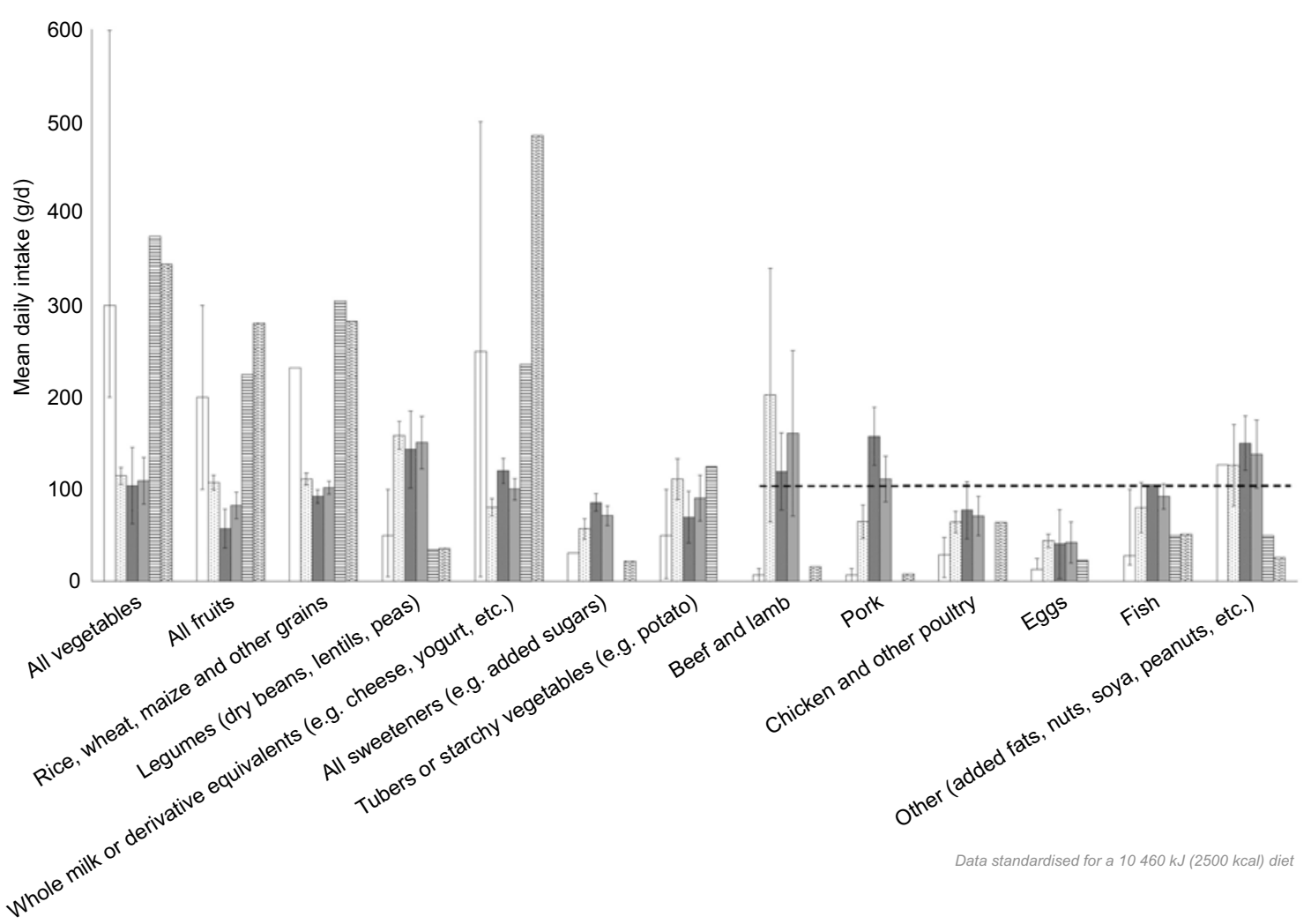

Fig. 2. Level of adherence to healthy and sustainable dietary patterns and average dietary cost among young adults in Albania. $\square$, EAT-Lancet, 罒, substantial at home eaters; $\square$, substantial out of home eaters; $\square$, overall diet; 目, Mediterranean diet; 圈, Dietary Approaches to Stop Hypertension; - - - -, recommendation based on average content of the Mediterranean diet for meat and meat products (i.e. lean meat/poultry/fish/eggs/nuts and seeds/legumes grouped together in dietary guidelines, not separately).

Table 4. Associations between healthy and sustainable diet indicators and BMI among young adults in Albania ( $n$ 289) ( $\beta$-Coefficients and standard errors)

\begin{tabular}{|c|c|c|c|c|c|c|}
\hline \multirow[b]{3}{*}{ Independent variable } & \multicolumn{6}{|c|}{ BMI $\left(\mathrm{kg} / \mathrm{m}^{2}\right)$} \\
\hline & \multicolumn{3}{|c|}{ Unadjusted model } & \multicolumn{3}{|c|}{ Adjusted model* } \\
\hline & $\beta$ & $\mathrm{SE}$ & $P$ & $\beta$ & SE & $P$ \\
\hline DASH (0-9 points) & $0 \cdot 1$ & 0.2 & 0.53 & 0.2 & 0.2 & 0.27 \\
\hline EAT (0-14 points) & -0.3 & 0.2 & 0.07 & -0.3 & 0.2 & 0.13 \\
\hline MDS (0-12 points) & 0.2 & 0.1 & 0.03 & 0.2 & 0.1 & 0.05 \\
\hline
\end{tabular}

$\beta$, Ordinary least-squares $\beta$-coefficient; DASH, Dietary Approaches to Stop Hypertension; EAT, EAT-Lancet diet score; MDS, Mediterranean diet score. * Adjusted models include sex and 'total energy intake (kJ)' as confounders.

\section{Acknowledgements}

We thank our colleagues from the Department of Public Health at the University of Medicine, Tirana who assisted the research and, in particular, Teuta Muhollari, an environmental toxicologist, for her invaluable comments. This paper is a contribution of the authors to the UN Decade of Action on Nutrition (2016-2025): https://www.un.org/nutrition/.

This work is supported by the EFOP-3.6.1-16-2016-00022 and GINOP-2.3.2-15-2016-00005 project. The project was co-financed by the European Union and the European Social Fund. There was no additional external funding received for this study. The supporters of the study had no role in study design, data collection, 
analysis, interpretation or writing of the manuscript. The corresponding author has full access to all of the data in the study and had the final responsibility for deciding to submit the manuscript for publication.

The authors' contributions were as follows: E. L. and G. H.-C. conceptualised the research; E. L. conducted and coordinated the research; E. L. lead the study design and data collection; E. L. and G. H.-C. developed the first draft and revised the manuscript; E. L. and G. H.-C. analysed data. Both authors read and approved the final manuscript.

The authors have no conflicts of interest to disclose.

\section{References}

1. Wells JC, Sawaya AL, Wibaek R, et al. (2019) The double burden of malnutrition: aetiological pathways and consequences for health. Lancet 395, 75-88.

2. Popkin BM, Corvalan C \& Grummer-Strawn LM (2020) Dynamics of the double burden of malnutrition and the changing nutrition reality. Lancet 395, 65-74.

3. GNR (2020) 2020 Global Nutrition Report: Action on Equity to End Malnutrition. Bristol, UK: Development Initiatives.

4. Lachat C, Otchere S, Roberfroid D, et al. (2013) Diet and physical activity for the prevention of noncommunicable diseases in low- and middle-income countries: a systematic policy review. PLoS Med 10, e1001465.

5. Miranda JJ, Barrientos-Gutiérrez T, Corvalan C, et al. (2019) Understanding the rise of cardiometabolic diseases in lowand middle-income countries. Nat Med 25, 1667-1679.

6. Stanaway JD, Afshin A, Gakidou E, et al. (2018) Global, regional, and national comparative risk assessment of 84 behavioural, environmental and occupational, and metabolic risks or clusters of risks for 195 countries and territories, 1990-2017: a systematic analysis for the Global Burden of Disease Study 2017. Lancet 392, 1923-1994.

7. Popkin BM (2006) Global nutrition dynamics: the world is shifting rapidly toward a diet linked with noncommunicable diseases. Am J Clin Nutr 84, 289-298.

8. Afshin A, Sur PJ, Fay KA, et al. (2019) Health effects of dietary risks in 195 countries, 1990-2017: a systematic analysis for the Global Burden of Disease Study 2017. Lancet 393, 1958-1972.

9. WCRF (2018) Diet, Nutrition, Physical Activity, and Cancer: A Global Perspective. Continuous Update Project Expert Report. London, UK: World Cancer Research Fund.

10. Marmot M (2018) Diet, cancer, and NCD prevention. Lancet Oncol 19, 863-864.

11. Smith LP, Ng SW \& Popkin BM (2013) Trends in US home food preparation and consumption: analysis of national nutrition surveys and time use studies from 1965-1966 to 2007-2008. Nutr J 12, 45.

12. Lachat C, Nago E, Verstraeten R, et al. (2012) Eating out of home and its association with dietary intake: a systematic review of the evidence. Obes Rev 13, 329-346.

13. Orfanos P, Naska A, Trichopoulou A, et al. (2009) Eating out of home: energy, macro- and micronutrient intakes in 10 European countries. The European Prospective Investigation into Cancer and Nutrition. Eur J Clin Nutr 63, S239-S262.

14. Headey DD \& Alderman HH (2019) The relative caloric prices of healthy and unhealthy foods differ systematically across income levels and continents. J Nutr 149, 2020-2033.

15. HLPE (2020) Food Security and Nutrition: Building a Global Narrative Towards 2030. A Report by the High Level Panel of Experts on Food Security and Nutrition of the Committee on
World Food Security. Rome, Italy: Committee on World Food Security

16. Kelly B, Vandevijvere S, Ng S, et al. (2019) Global benchmarking of children's exposure to television advertising of unhealthy foods and beverages across 22 countries. Obes Rev 20, 116-128.

17. Harris J, Frazier Iii W, Kumanyika S, et al. (2019) Increasing Disparities in Unhealthy Food Advertising Targeted to Hispanic and Black Youth. In Rudd Report. Hartford, CT: UCONN Rudd Center for Food Policy and Obesity.

18. Strupat C, Farfan G, Moritz L, et al. (2019) Obesity and food away from home: what drives the socioeconomic gradient in excess body weight? In Policy Research Working Papers, vol. 9066. Washington, DC: World Bank.

19. Wolfson JA \& Bleich SN (2015) Is cooking at home associated with better diet quality or weight-loss intention? Public Health Nutr 18, 1397-1406.

20. Bes-Rastrollo M, Basterra-Gortari FJ, Sánchez-Villegas A, et al. (2009) A prospective study of eating away-from-home meals and weight gain in a Mediterranean population: the SUN (Seguimiento Universidad de Navarra) cohort. Public Health Nutr 13, 1356-1363.

21. Clifford Astbury C, Penney TL \& Adams J (2019) Comparison of individuals with low versus high consumption of home-prepared food in a group with universally high dietary quality: a cross-sectional analysis of the UK National Diet \& Nutrition Survey (2008-2016). Int J Behav Nutr Phys Act 16, 9.

22. Astbury CC, Penney TL \& Adams J (2018) Is eating homeprepared food a necessary condition for high dietary quality? Cross-sectional analysis of the UK National Diet and Nutrition Survey, 2008-16. Lancet 392, S18.

23. Kant AK \& Graubard BI (2018) A prospective study of frequency of eating restaurant prepared meals and subsequent 9-year risk of all-cause and cardiometabolic mortality in US adults. PLOS ONE 13, e 0191584.

24. Seow DYB, Haaland B \& Jafar TH (2015) The association of prehypertension with meals eaten away from home in young adults in Singapore. Am J Hypertens 28, 1197-1200.

25. Nishida C, Uauy R, Kumanyika S, et al. (2004) The joint WHO/ FAO expert consultation on diet, nutrition and the prevention of chronic diseases: process, product and policy implications. Public Health Nutr 7, 245-250.

26. Herforth A, Arimond M, Álvarez-Sánchez C, et al. (2019) A global review of food-based dietary guidelines. Adv Nutr 10, 590-605.

27. Estruch R, Ros E, Salas-Salvadó J, et al. (2018) Primary prevention of cardiovascular disease with a Mediterranean diet supplemented with extra-virgin olive oil or nuts. $N$ Engl J Med 378, e34.

28. Salehi-Abargouei A, Maghsoudi Z, Shirani F, et al. (2013) Effects of Dietary Approaches to Stop Hypertension (DASH)-style diet on fatal or nonfatal cardiovascular diseases-incidence: a systematic review and meta-analysis on observational prospective studies. Nutrition 29, 611-618.

29. Yang Z-Q, Yang Z \& Duan M-L (2019) Dietary Approach to Stop Hypertension diet and risk of coronary artery disease: a metaanalysis of prospective cohort studies. Int J Food Sci Nutr 70, 668-674.

30. Knuppel A, Papier K, Key TJ, et al. (2019) EAT-Lancet score and major health outcomes: the EPIC-Oxford study. Lancet 394, 213-214.

31. Poore J \& Nemecek T (2018) Reducing food's environmental impacts through producers and consumers. Science 360, 987. 
32. Swinburn BA, Kraak VI, Allender S, et al. (2019) The global syndemic of obesity, undernutrition, and climate change: the Lancet Commission report. Lancet 393, 791-846.

33. Clark MA, Springmann M, Hill J, et al. (2019) Multiple health and environmental impacts of foods. Proc Natl Acad Sci US A $\mathbf{1 1 6}$ 201906908.

34. Willett W, Rockström J, Loken B, et al. (2019) Food in the Anthropocene: the EAT-Lancet Commission on healthy diets from sustainable food systems. Lancet 393, 447-492.

35. Llanaj E, Ádány R, Lachat C, et al. (2018) Examining food intake and eating out of home patterns among university students. PLOS ONE 13, e0197874.

36. Gibson RS \& Ferguson EL (2008) An Interactive 24-hour Recall for Assessing the Adequacy of Iron and Zinc Intakes in Developing Countries. Washington, DC: International Food Policy Research Institute and International Center for Tropical Agriculture.

37. INSTAT (2017) Students enrolled by Faculty and Programmes, academic year 2016-2017, in Public Education. Themes: Labour Market and Education. http://www.instat.gov.al/media/ 2923/student\%C3\%AB-p\%C3\%ABr-\%C3\%A7do-fakultet-dhesipas-programit-viti-akademik-2016-2017-n\%C3\%AB-arsiminpublik.xlsx (accessed August 2020).

38. Signorini DF (1991) Sample size for Poisson regression. Biometrika 78, 446-450.

39. Serra-Majem L, Ribas L, Ngo J, et al. (2004) Food, youth and the Mediterranean diet in Spain. Development of KIDMED Mediterranean Diet Quality Index in children and adolescents. Public Health Nutr 7, 931-935.

40. Mellen PB, Gao SK, Vitolins MZ, et al. (2008) Deteriorating dietary habits among adults with hypertension: DASH Dietary Accordance, NHANES 1988-1994 and 1999-2004. JAMA Intern Med 168, 308-314.

41. Appel LJ, Moore TJ, Obarzanek E, et al. (1997) A clinical trial of the effects of dietary patterns on blood pressure. $N$ Engl J Med 336, 1117-1124.

42. Sacks FM, Svetkey LP, Vollmer WM, et al. (2001) Effects on blood pressure of reduced dietary sodium and the Dietary Approaches to Stop Hypertension (DASH) diet. $N$ Engl J Med 344, 3-10.

43. Willett WC, Howe GR \& Kushi LH (1997) Adjustment for total energy intake in epidemiologic studies. Am J Clin Nutr 65 1220S-1228S.

44. World Health Organization (2012) Guideline: Sodium Intake for Adults and Children. Geneva, Switzerland: WHO.

45. Nugent R, Levin C, Hale J, et al. (2020) Economic effects of the double burden of malnutrition. Lancet 395, 156-164.

46. Béné C, Prager SD, Achicanoy HAE, et al. (2019) Global map and indicators of food system sustainability. Sci Data 6, 279.

47. Bejtja G, Selfo M, Ceka N, et al. (2008) Recommendations on Healthy Nutrition in Albania (Albanian: Rekomandime për një ushqyerje të shëndetshme në Shqipëri). Tirana, Albania: South-Eastern Europe Health Network, World Health Organization and Ministry of Health.

48. Sinha R, Cross AJ, Graubard BI, et al. (2009) Meat intake and mortality: a prospective study of over half a million people. Arch Intern Med 169, 562-571.

49. Bellavia A, Stilling F \& Wolk A (2016) High red meat intake and all-cause cardiovascular and cancer mortality: is the risk modified by fruit and vegetable intake? Am J Clin Nutr 104, 1137-1143.

50. Vilarnau C, Stracker DM, Funtikov A, et al. (2019) Worldwide adherence to Mediterranean Diet between 1960 and 2011 Eur J Clin Nutr 72, 83-91.

51. da Silva R, Bach-Faig A, Raidó Quintana B, et al. (2009) Worldwide variation of adherence to the Mediterranean diet, in 1961-1965 and 2000-2003. Public Health Nutr 12, 1676-1684.
52. Bezerra IN, Junior EV, Pereira RA, et al. (2015) Away-fromhome eating: nutritional status and dietary intake among Brazilian adults. Public Health Nutr 18, 1011-1017.

53. Naska A, Katsoulis M, Orfanos P, et al. (2015) Eating out is different from eating at home among individuals who occasionally eat out. A cross-sectional study among middle-aged adults from eleven European countries. Br J Nutr 113, 1951-1964.

54. Fleischhacker SE, Evenson KR, Rodriguez DA, et al. (2011) A systematic review of fast food access studies. Obes Rev 12, e460-e471.

55. Hanley-Cook GT, Argaw AA, de Kok BP, et al. (2020) EATLancet diet score requires minimum intake values to predict higher micronutrient adequacy of diets in rural women of reproductive age from five low- and middle-income countries. Br J Nutr (epublication ahead of print version 30 September 2020).

56. Branca F, Demaio A, Udomkesmalee E, et al. (2020) A new nutrition manifesto for a new nutrition reality. Lancet 395, 8-10.

57. Popkin BM, Corvalan C \& Grummer-Strawn LM (2019) Dynamics of the double burden of malnutrition and the changing nutrition reality. Lancet 395, 65-74.

58. Hawkes C, Ruel MT, Salm L, et al. (2020) Double-duty actions: seizing programme and policy opportunities to address malnutrition in all its forms. Lancet 395, 142-155.

59. Monsivais P, Rehm CD \& Drewnowski A (2013) The DASH diet and diet costs among ethnic and racial groups in the United States. JAMA Intern Med 173, 1922-1924.

60. Hirvonen K, Bai Y, Headey D, et al. (2019) Affordability of the EAT-Lancet reference diet: a global analysis. Lancet Glob Health 8, Pe59-Pe66.

61. Tong TYN, Imamura F, Monsivais P, et al. (2018) Dietary cost associated with adherence to the Mediterranean diet, and its variation by socio-economic factors in the UK Fenland Study. BrJ Nutr 119, 685-694.

62. Steenhuis IHM, Waterlander WE \& de Mul A (2011) Consumer food choices: the role of price and pricing strategies. Public Health Nutr 14, 2220-2226.

63. Hanley-Cook GT, Tung JYA, Sattamini IF, et al. (2020) Minimum Dietary Diversity for Women of Reproductive Age (MDD-W) data collection: validity of the list-based and open recall methods as compared to weighed food record. Nutrients 12, 2039.

64. Beaton GH (1994) Approaches to analysis of dietary data: relationship between planned analyses and choice of methodology. Am J Clin Nutr 59, 253S-261S.

65. Institute of Medicine Subcommittee on Interpretation and Uses of Dietary Reference Intakes \& Institute of Medicine Standing Committee on the Scientific Evaluation of Dietary Reference Intakes (2000) DRI Dietary Reference Intakes: Applications in Dietary Assessment. Washington, DC: National Academies Press.

66. INSTAT (2017) Students enrolled by Faculty and Programmes, academic year 2016-2017, in Public Education. http://www. instat.gov.al/media/4616/tab4.xlsx (accessed August 2020).

67. Mullie P, Clarys P, Hulens M, et al. (2010) Dietary patterns and socioeconomic position. Eur J Clin Nutr 64, 231-238.

68. Raxhimi A (2019) Mass Student Protests Bring Down Albania's Science Minister. https://www.nature.com/articles/d41586019-00144-7 (accessed September 2020).

69. Llanaj E, D'Haese M, Lachat C (2016) Food Intake and Eating Out of Home Patterns Amongst University Students of Tirana. Albania: Ghent University.

70. Rippin HL, Hutchinson J, Evans CEL, et al. (2018) National nutrition surveys in Europe: a review on the current status in the 53 countries of the WHO European region. Food Nutr Res 62, 10.29219/fnr.v62.1362. 